\title{
Una aproximación cronológica al centro administrativo Hualfín Inka, Catamarca, Argentina
}

\author{
Julieta LYNCH \\ Departamento Científico de Arqueología, Museo de La Plata \\ julietalynch@yahoo.es
}

Recibido: 25 de abril de 2011

Aceptado: 24 de enero de 2012

RESUMEN

El Tawantinsuyu se extendió a lo largo de la cordillera andina desde el sur de Colombia hasta el centro de Chile y Noroeste de Argentina, incorporando a lo largo de este territorio poblaciones cultural y ambientalmente muy diversas. Es bien sabido, a través del análisis de los diferentes cronistas, que el Noroeste Argentino se anexó al Tawantinsuyu hacia el 1471 d.C., bajo la dominación de Topa Inka Yupanqui. Sin embargo, en las últimas décadas se han podido constatar nuevas fechas para sitios incaicos encontrados a lo largo de Argentina y Chile que dan cuenta de una ocupación más temprana, llegando incluso algunos hasta principios del siglo XV. En este trabajo se presenta la información arqueológica generada a partir de los análisis espaciales, arquitectónicos, cronológicos y de los materiales de excavación del sitio Hualfín Inka (Hualfín, Catamarca), con el fin de reconstruir la funcionalidad de este sitio y su relación con el paisaje sociopolítico del Valle de Hualfín para el período de ocupación incaica del Noroeste Argentino. A partir de las excavaciones realizadas se han podido distinguir sectores públicos tales como kallankas, ushnu, plaza intramuros, así como sectores atribuibles a actividades cotidianas o domésticas, ubicándolo como un centro administrativo para los primeros años de la ocupación inca en la región.

Palabras clave: Arquitectura, funcionalidad, Hualfín Inka, cronología, Catamarca.

\section{A Chronological Approach to the Administrative Center of Hualfin Inka, Catamarca, Argentina}

\begin{abstract}
The Tawantinsuyu spread along the Andes from the south of Colombia to center of Chile and Argentine Northwest, incorporating along this territory cultural and environmental diverse population. It is well known, through the analysis of the different chronicles registered for the Inka's Empire, that the incorporation of the Argentine Northwest to the Tawantinsuyu was at 1471 A.D., under the domination of Topa Inka Yupanqui. Nevertheless, in the last decades new dates has been obtained for Inka's archaeological sites founded along Argentina and Chile, which show an early occupation, some of them dating from the beginning of the $15^{\text {th }}$ century. This paper presents archaeological information from spatial, architectural, chronological and material analyses from Hualfín Inka (Hualfin, Catamarca). The aim is reconstructing the site functionality and its relationship to sociopolitical aspects in Hualfin Valley during Inca's occupation in Northwest Argentina. The results from excavations allowed us to identifiy sectors with Inka public architecture, such as kallankas, ushnu, intrawalls square, and at the same time we found sectors for common life activities, pointing that the site was an administrative center for the first time of Inca's occupation in this region.
\end{abstract}

Keys words: Architecture, functionality, Hualfín Inka, chronology, Catamarca

Sumario: 1. Introducción. 2. La ocupación incaica en el valle de Hualfín. 3. Antecedentes y descripción del sitio arqueológico Hualfín Inka. 4. Excavaciones en las principales estructuras del sitio y resultados. 5. Cronología incaica para el NOA: relación del caso de estudio e implicaciones. 6. Consideraciones finales. 7. Referencias bibliográficas. 


\section{Introducción}

El dominio incaico en el Noroeste Argentino se produjo una vez sofocada la gran rebelión de los collas contra el imperio. El Inca Tupac Yupanqui, hacia 1470, procedió a conquistar el sur de Bolivia, el Noroeste Argentino y el norte de Chile (Ibarra 1994: 415). Sin embargo, la conquista en los Andes Meridionales no duró más de sesenta años, tiempo insuficiente para que las culturas anteriores desapareciesen en forma definitiva, de modo que ellas continuaron en gran parte hasta la época de la conquista española, incluso hasta un siglo más tarde (Williams 2004: 209).

A lo largo de las investigaciones desarrolladas sobre la expansión y extensión del imperio incaico y sus fronteras, se han producido numerosas discusiones tales como el trabajo propuesto por Dillehay y Netherly (1988: 1-33), en donde resaltan las fronteras tanto internas como externas para la dinámica del imperio incaico. Sin embargo, actualmente se puede decir que, al menos desde la perspectiva geográfica, el debate se ha estabilizado y se acepta, en líneas generales, que el espacio geográfico ocupado por el imperio inca (Figura 1) se desarrolló a lo largo de la cordillera de los Andes en el continente sudamericano, desde unos cientos de kilómetros al norte de la capital ecuatoriana (Quito) hasta el río Maipo, en la cuenca de Santiago en Chile (Silva 1957: 46) -o el Cachapoal según Stehberg y Rodríguez (1995: 55)- y el valle de Uspallata, al Norte de la provincia de Mendoza, Argentina, cubriendo una longitud aproximada de 6.000 kilómetros de norte a sur. En sentido Este-Oeste, se puede decir que su extensión coincidió con la cordillera andina, con algunos sitios ubicados próximos a la costa pacífica hacia el Oeste y al Este, sobre la faja ecológico-cultural que forma el ecotono de las yungas y las florestas amazónicas que marcan el fin de la cordillera de los Andes (Raffino y Stehberg 1997: 343-346.)

En este breve periodo los incas extendieron sus fronteras y dominación sociopolítica sobre los reinos y etnias del altiplano, la sierra, los valles y la costa pacífica, ampliando sus límites desde el Cuzco a lo largo de la cordillera de los Andes, cubriendo una superficie de dos millones de kilómetros cuadrados. Se estima que en el momento de máxima expansión había una población total aproximada de seis a doce millones de habitantes, todos bajo un estricto sistema de tributos y burocracia creados por los incas, utilizando e imponiendo la lengua quechua en casi todo el ámbito de su dominio y conformando uno de los estados más extensos y poblados de la América prehispánica (D’Altroy 1987: 79; Stehberg y Rodríguez 1995: 53).

Sin embargo, actualmente el gran debate se ha trasladado hacia el problema cronológico, sobre todo referido a cuándo comienza su expansión la sociedad incaica, en qué momento ingresa en cada región particular o la confianza en las genealogías dinásticas construidas por los cronistas, que son el eje de una discusión que aún requiere mucho trabajo antes de poder mostrar un corpus sólido de conocimiento fundado.

Igualmente se sabe que entre las cualidades más notables del imperio estuvo la capacidad del estado para amalgamar las poblaciones locales, tan disimiles cultural y ambientalmente, bajo su dominación. En este sentido la aplicación de su política interna flexible favoreció la adecuación a las situaciones locales, sin por ello perder de vista los intereses del imperio (González y Tarragó 2004: 401; Williams 2004: 210).

El presente trabajo contribuye al conocimiento de la política incaica implementada en el sector Norte del Valle de Hualfín, provincia de Catamarca, a través del estudio 
del sitio denominado Hualfin Inka, el cual presenta una arquitectura de filiación incaica (Lynch 2010: 164). Este yacimiento cuenta con sectores de carácter público y sectores vinculados a actividades cotidianas. Por otra parte, uno de los aspectos más importantes que se exponen en este trabajo son los primeros fechamientos absolutos para el sitio, contribuyendo a la problemática planteada en los últimos años sobre la cronología incaica para la anexión del Noroeste Argentino.

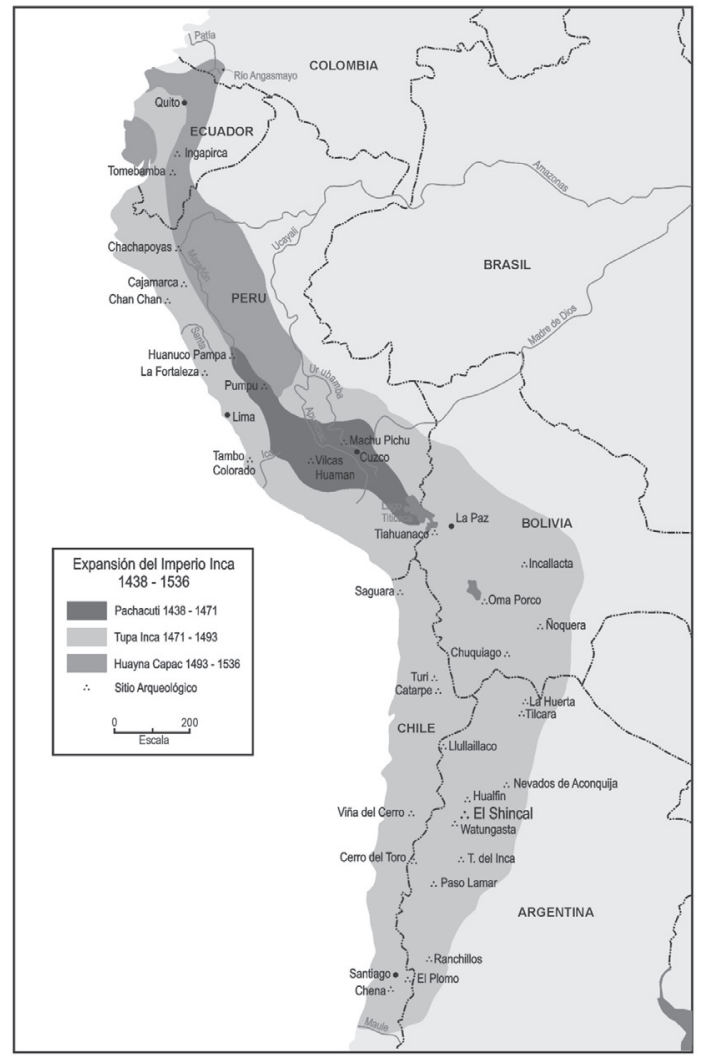

Figura 1: Mapa de extensión del Tawantinsuyu y las regiones anexadas.

\section{La ocupación incaica en el valle de Hualfín}

En el Noroeste Argentino se encuentran numerosas instalaciones con arquitectura incaica, pudiéndose diferenciar centros administrativos, tambos, almacenes, lugares vinculados a la actividad agrícola, etc. Si bien los mismos comparten ciertos rasgos de urbanismo y planificación, la infraestructura implementada en el Noroeste Argentino (NOA) no fue la misma para los sectores más cercanos al Cuzco, la capital del imperio. Ello se debe principalmente a la naturaleza de la materia prima disponible en las regiones que el Incario iba anexando a medida que se expandía. 
El denominado «Valle de Hualfín», en sentido amplio, corresponde al área recorrida por el río Hualfín y sus afluentes, abarcando una extensión aproximada de $2.000 \mathrm{~km}^{2}$ (Figura 2). Se encuentra ubicado en la Región Central de la Provincia de Catamarca, en la denominada Provincia Geológica de las Sierras Pampeanas Noroccidentales (Caminos 1979: 225; González Bonorino 1950: 89). En la región predomina un clima árido o semiárido, donde las aguas superficiales son muy escasas; los ríos y arroyos son generalmente de poco caudal y de régimen transitorio (Caminos 1979: 282). El río Hualfín es, generalmente, un curso de poco caudal en los meses de temporada seca (abril-noviembre) y aumenta en temporada húmeda, los meses de verano (diciembre-marzo). La vegetación se encuentra formada principalmente por jarillas, cardones, chañares y, cercanos a la población local, algarrobos (Lynch et al. 2006: 198).

Debido a sus características naturales favorables, el Valle de Hualfín presentó unas condiciones óptimas para el asentamiento de poblaciones humanas. Situado en las proximidades de los valles calchaquíes y la Puna, fue paso obligado hacia el valle de Abaucán y Chile por un lado y hacia las regiones de La Rioja y Cuyo por otro (González y Cowgill 1975: 383-395).

\section{Antecedentes y descripción del sitio arqueológico Hualfín Inka}

El sitio Hualfín Inka se encuentra entre las coordenadas $27^{\circ} 13^{\prime} 46^{\prime \prime}$ de latitud sur y $66^{\circ} 48^{\prime} 55^{\prime}$ "de longitud oeste, emplazado frente a la ruta Nacional $\mathrm{N}^{\circ} 40$, sobre la margen izquierda del río homónimo (ver Figura 2), en una terraza elevada, a una altura de $1.880 \mathrm{msnm}$.

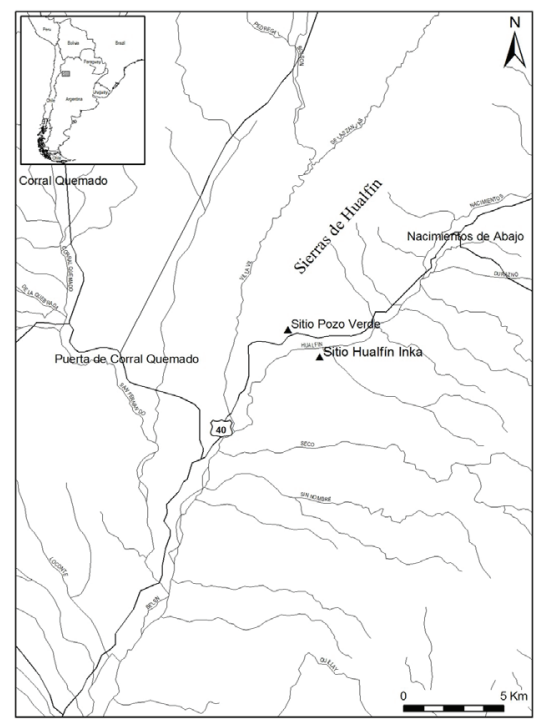

Figura 2: Ubicación del Valle de Hualfín. 
El primer registro del mismo fue llevado a cabo por Carlos Bruch entre los años 1896-1897, cuando fue llamado por Francisco Perito Moreno para realizar colecciones superficiales en la zona del Valle de Hualfín, Catamarca. A su regreso publicó, en su trabajo terminado hacia el 1901, una lámina de las ruinas sin escala ubicadas sobre la orilla este del río Hualfín.

Sin embargo, los primeros trabajos realizados para el sitio fueron los hechos por el Dr. Raffino y colaboradores, quienes realizaron un nuevo plano y una reconstrucción arquitectónica tentativa, sin realizar ninguna intervención arqueológica. La reconstrucción fue hecha apelando a la posición de los edificios, ubicación y asociación entre sí y con el terreno, dado que un gran porcentaje del material pétreo había sido extraído del sitio y utilizado para la construcción de las defensas del río Hualfín y la edificación moderna. (Raffino et al. 1982: 478). Pero es a partir del año 2005 cuando se realizaron las primeras excavaciones sistemáticas en el sitio a cargo de la autora de este artículo (Lynch 2010: 172, Lynch et al. 2006: 197, Lynch et al. 2007: 527).

El área construida denota una clara planificación de tipo damero regular (Figura 3), similar a otros sitios incaicos de la región del Noroeste Argentino, ocupando 5,4 ha en las cuales los muros de todas las estructuras fueron construidos a partir de rocas subglobulares a subcuadrangulares, donde las mismas no presentan caras canteadas pero sí denotan una selección arbitraria de aquellas con caras más planas, provenientes probablemente del río, ubicado a pocos metros de distancia (Lynch et al. 2007: 528).

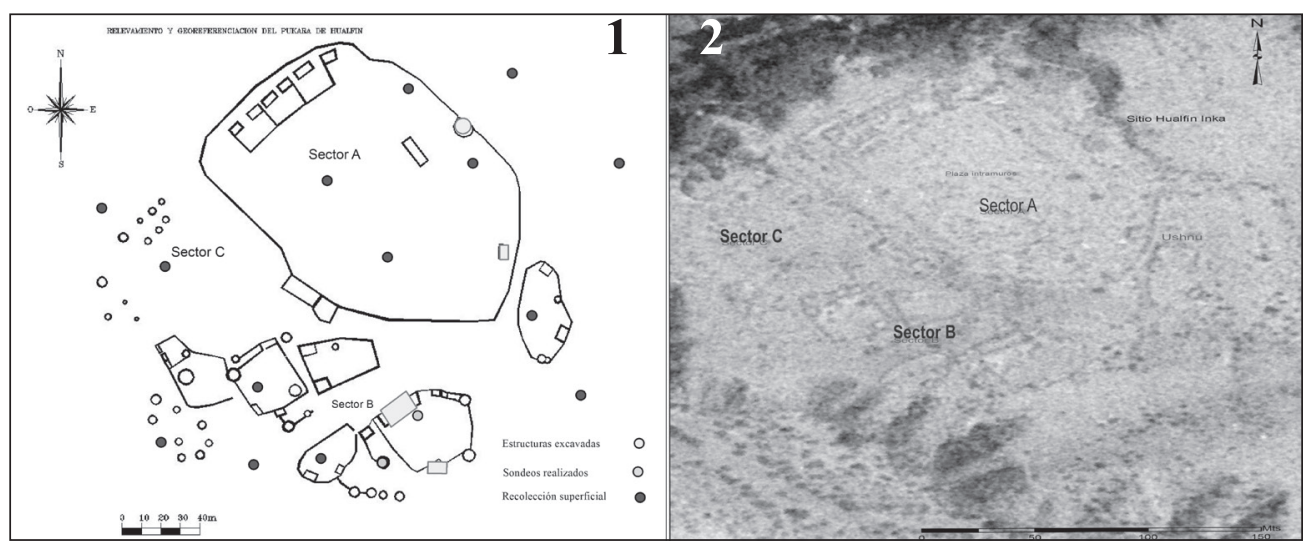

Figura 3: (1) Plano actualizado del sitio Hualfín Inka. (2) Foto aérea del sitio (1:20.000).

Los muros de piedra son dobles con relleno de adobe y ripio, y presentan dimensiones entre 0,60 y $0,70 \mathrm{~m}$ de ancho. Con fines puramente descriptivos, el sitio fue dividido en tres sectores: A, B y C (Raffino et al.1982: 478; Lynch 2010: 150). El sector A se ubica hacia el NE, tiene una superficie de aproximadamente $15.000 \mathrm{~m}^{2}$ con forma de polígono irregular y está delimitada por un muro perimetral. Esta estructura es una plaza intramuros o aukaipata, con estructuras adosadas en su interior (kallanka, torreón, ushnu). A través de datos etnohistóricos se ha identificado que la aukaipata o plaza principal habría sido utilizada como un centro de aglomeración de 
gran cantidad de personas, eran amplias, de forma trapezoidal y en ellas se realizaban actividades religiosas y sociales. A su vez, el rito de la reciprocidad se efectuaba en la gran plaza, en donde los ayllu y linajes reales se reunían a comer, beber y bailar las danzas ceremoniales del calendario cuzqueño.

En ella se efectuaban, asimismo, celebraciones del triunfo de los ejércitos incas, que consistían en extender por el suelo el botín obtenido y a los señores presos. Sobre todo ello se paseaba el soberano en signo de sumisión de sus enemigos y de poder sobre sus nuevas adquisiciones territoriales. Se puede decir que este espacio se establecía especialmente para posibilitar y dar contexto a prácticas constitutivas y legitimadoras del poder del Estado, y por ende de las elites (muchas veces elites locales que se plegaban al nuevo sistema de poder para mantener ciertos beneficios). Nielsen (2006) distingue también estos espacios no sólo por la congregación frecuente de grandes grupos de personas sino porque además, en el plano andino, las acciones desarrolladas en las mismas podrían mostrar una estrecha y explícita relación con la imagen de la comunidad sobre sí misma, las autoridades y el conjunto de valores apropiados y defendidos. Las plazas de los sitios Los Amarillos (Jujuy) y Laqaya (Lípez) les han demostrado la centralidad del culto a los antepasados en grupos de jerarquías corporativas y descentralizadas políticamente. Las plazas cumplirían un rol fundamental en la unión de la comunidad integrándola en el mismo espacio compartido (Nielsen 2006: 63-70). Pero como bien lo señala el autor, la hawkaipata inca pone en primer plano la institución del Estado más que la representación de los ancestros, aunque el poder político pueda recurrir aún a discursos sobre el pasado, pero ya con significados de carácter panandino más que localizadas prácticas de comunidades concretas. Por su parte, Moore (1996: 789-802) ha discutido comparativamente el significado, desde el punto de vista de las relaciones sociales jerárquicas, de este tipo de manifestaciones espaciales. En general, las plazas en los Andes fueron el espacio para los rituales principales combinando discursos, música, danza y despliegues en ceremonias que fusionaban comunidades, legitimaban distinciones y jerarquía social y consolidaban las creencias cosmogónicas. Moore destaca de las plazas incaicas el hecho de que involucraran grandes grupos de gente en rituales comunitarios, a diferencia de otro tipo de sociedades andinas como los Chimú o Tiwanaku. Volviendo a la plaza de Hualfín Inka vemos a su vez, asociado a ella, un muro perimetral (ver Figura 3) que recorre la misma delimitando otras estructuras de gran importancia en asentamientos incaicos, que se detalla a continuación.

Una de ellas es una estructura rectangular emplazada sobre el lateral Este de la plaza; se trata de una verdadera plataforma artificial de carácter ceremonial o uhsnu (Hyslop 1990: 69; Lynch et al. 2010; Raffino 1981; Zuidema 1979) de forma rectangular de 3,5 x 7,5 $\mathrm{m}$ y al menos $1 \mathrm{~m}$ de altura. Está separada del muro perimetral unos $4 \mathrm{~m}$ y presenta un acceso por una escalera de, cuanto menos, tres peldaños sobre la pared que mira hacia la plaza. Los muros son dobles, con un espesor que oscila entre los 0,50-0,60 m, tienen un cementante compuesto de barro y ripio y no presentan caras canteadas, aunque si podría haber una selección de las caras más planas dispuestas hacia el exterior (Lynch et al. 2007: 528). Uno de los mayores estudiosos en el tema fue Zuidema (1979) que ha establecido que este espacio se comportaría como una forma de axis mundi o eje de conexión vertical donde se realizan actos rituales 
como forma de conectar espacio y tiempo, ancestros y picos montañosos. Sugirió además que éste tiene un carácter de acceso al «mundo subterráneo» (Zuidema 1979: 332-336), asociando la acción de «chupar» o absorber las ofrendas líquidas en los rituales realizados. Pero, a la vez, menciona que el ushnu en Cuzco fue un centro de observaciones astronómicas y que posiblemente ello influyó en el trazo del plano general de esa ciudad (Zuidema 1979: 343). Este rasgo existe a lo largo de todo el espacio dominado por los incas desde Ecuador hasta Argentina (Meddens 1997: 6), con mayor preeminencia al norte del lago Titicaca (Farrington 1999: 55; Raffino 2004).

Otra de las estructuras encontradas en el Sector A es la kallanka, una estructura característica de la arquitectura inca: halls o galpones largos y rectangulares sin divisiones. En general se encuentran sobre las plazas y sus puertas dan hacia las mismas. Aparentemente su funcionalidad estaría ligada como residencia temporal de sus ocupantes, siendo los mismos soldados, o como residencia de cualquiera que estuviera en relación con el estado (Hyslop 1990: 18). En el Cuzco, por ejemplo, las kallankas eran construidas a mayor escala y destinadas a ceremonias o festejos (Pizarro 1978: 160).

En este sector también se excavó una estructura circular, ubicada espacialmente hacia el NE de la plaza, designado como un torreón defensivo (Raffino et al. 1982: 478), pero al encontrarse sobre el muro perimetral de la plaza principal y con la misma altitud, difícilmente podríamos distinguirlo con dicha función (Lynch 2010: 290). En él se realizaron excavaciones pudiendo recuperar diferentes materiales culturales, entre los cuales los más numerosos corresponden a la cerámica, representada mayoritariamente por el tipo Belén negro sobre rojo y el tipo Tosco, donde no se registró pintura alguna, mientras que en menor proporción se registraron tiestos incaicos (Lynch 2010: 238).

En relación al Sector B, el mismo contiene un conjunto de tres Rectángulos Perimetrales Compuestos (en adelante RPC), situados aproximadamente en línea, que poseen recintos rectangulares y circulares (ver Figura 3). La planta de estos conjuntos es irregular, circunstancia que no parece responder a un condicionamiento topográfico, puesto que la superficie no es especialmente abrupta. En el grupo de construcciones intermedio se encuentran cuatro recintos rectangulares, uno de los cuales, de dimensiones mayores, correspondería a otra kallanka.

El Sector C se localiza al SO de la plaza y se compone de un grupo de cuatro RPC, de perímetro más regular que los del Sector $\mathrm{B}$, y tres grupos de recintos circulares agrupados, que fueron interpretados como collcas (Raffino et al. 1982: 480; Lynch 2010: 169).

Por último, cabe resaltar que los emplazamientos encontrados para el Valle de Hualfín, atribuibles al espacio de tiempo inmediatamente anterior a la llegada del Inca o período de Desarrollos Regionales, entre el 900/1000-1480 d.C., corresponden mayoritariamente a sitios emplazados en altura, con la existencia de ciertas barreras, tales como murallas de circunvalación, sistemas de muros múltiples, ríos, cárcavas, riscos, etc., sin descartar la posibilidad de barreras de carácter perecedero o móviles (plantas, barro, troncos), difícilmente observables en el registro arqueológico (Balesta y Wynveldt 2009: 58). Estos emplazamientos difieren notablemente de los sitios inca ubicados en el sector centro-oeste de Catamarca como Quillay, El Shincal, Watungasta o el propio Hualfín Inka. 


\section{Excavaciones en las principales estructuras del sitio y resultados}

Durante las excavaciones realizadas desde el año 2005 en el sitio se ha podido diferenciar un solo evento de ocupación. Se han excavado seis estructuras, entre las cuales se pueden diferenciar sectores con evidencia de actividades vinculadas al uso cotidiano (Recinto 1, Sector B), así como otras vinculadas a actividades de tipo más público, como el ushnu y la kallanka.

Se ha podido diferenciar un perfil estratigráfico que se repite a lo largo de todo el sitio (Figura 4), el cual puede resumirse así: un Horizonte A, muy poco desarrollado $(0-1 \mathrm{~cm})$, de color castaño claro, textura franco-arenosa, estructura laminar, fina y débil, friable, con presencia escasa de raíces; un Horizonte C (1-0,65 m) cuya coloración es castaño clara, textura franco-arenosa-guijarrosa, estructura laminar, fina, débil, friable, con presencia común de raíces. En este horizonte se encuentran zonas de laminación por selección hídrica (lluvias) (Lynch et al. 2007: 527). Dentro de este Horizonte $\mathrm{C}$ es donde se encuentran inmersos los materiales arqueológicos de las estructuras trabajadas.

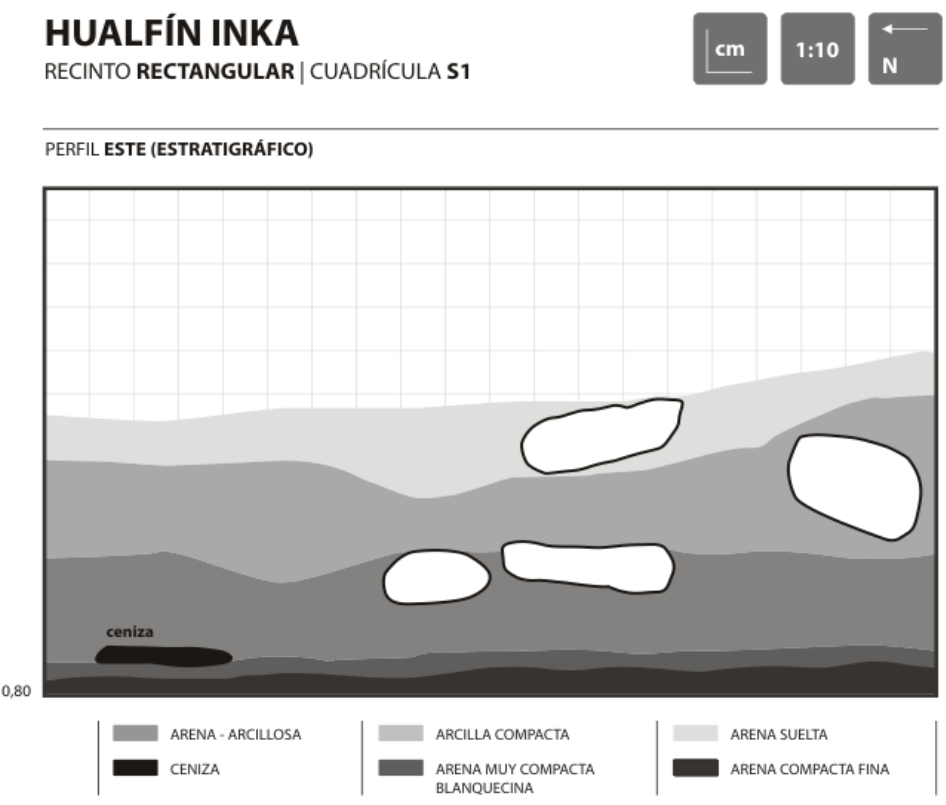

Figura 4: Perfil estratigráfico.

La excavación del ushnu produjo el hallazgo de una variedad de materiales arqueológicos entre los que se cuentan restos cerámicos, óseos, líticos y arqueobotánicos. Asimismo, si bien cuantitativamente escasos, también se identificaron restos de naturaleza malacológica, como es el caso de pequeñas cuentas de nacar. Un dato remarcable es la relativa abundancia de material recuperado en esta estructura en comparación al resto de las excavadas en las que el registro fue escaso en comparación a la superficie total de ex- 
cavación (Lynch et al. 2010). Se detallan a continuación las características sobresalientes de los distintos materiales recuperados por estructura trabajada.

Ushnu: En cuanto a la cerámica el conjunto total de material recuperado en una superficie de $8 \mathrm{~m}^{2}$ es de 71 fragmentos ( $\mathrm{n}=71$ ). Dentro de ellos, es proporcionalmente importante la presencia de estilos decorativos asociados al período Tardío o de Desarrollos Regionales (900-1480 d.C.), en relación a los incaicos. En este sentido, se ha podido constatar un mayor porcentaje del estilo local denominado Belén (Figura 5.1) y Santa María (Figura 5.2), mientras que el estilo Inca (1480-1532 d.C.) se encuentra presente tan solo en un $7 \%$ del total de la muestra obtenida. Los materiales de tipo Tosco sin decoración son, sin embargo, los más numerosos (Lynch y Páez 2011). Asociado a este material cerámico se encontraron restos óseos de animales, familias de Camélidae y Cérvidae (41\%) (Lynch 2010, Lynch et al. 2007); artefactos líticos (Figura 5.3) correspondientes a lascas, lascones, núcleos y mayormente desechos de talla. Las distintas materias primas que componen el conjunto incluyen basalto, cuarzo, cuarcita, sílices de distinta coloración y arenisca (Lynch 2010: 36, Lynch y Lynch 2010: 1687). El registro arqueobotánico recuperado cuenta con una importante abundancia de carbones de diferentes tamaños, diferenciándose entre los mismos restos de maíz (Zea mays) (Lynch 2010). Dentro de las plantas cultivadas destacamos el hallazgo de un grano de poroto (Phaseolus vulgaris). Con una incidencia muy baja se identificaron también restos de vegetales silvestres como chañar (Geoffroea decorticans) y algarrobo (Prosopis sp). De cualquier forma, los restos arqueobotánicos más numerosos fueron fragmentos de leños carbonizados, lo que evidencia una destacable presencia de fogones dentro de esta estructura arquitectónica. De aquí se obtuvo una de las muestras datadas (AA 85878/Cuad. S2, fogón, Niv.12, 0,90 m, carbón vegetal), dando una edad radiocarbónica de $515 \pm 42 \mathrm{AP}$.

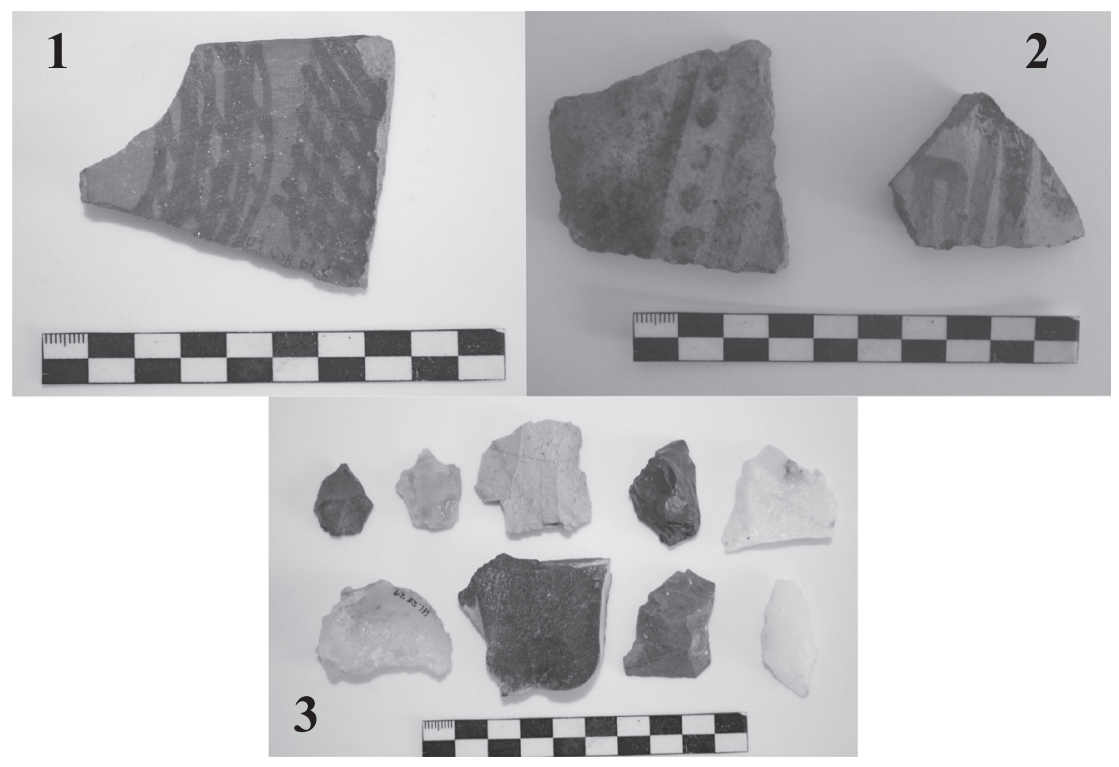

Figura 5: Material estratigráfico procedente del ushnu. (1) Tipo cerámico Belén negro sobre rojo. (2) Tipo cerámico Santa María. (3) Artefactos líticos. 
Kallanka: En el Sector B, el recinto denominado de esta manera por sus medidas y por sus características arquitectónicas, proporcionó muy poco material en relación con el tamaño arquitectónico $(25 \times 8 \mathrm{~m})$. Dentro de los diferentes materiales podemos decir que la cerámica fue el material más abundante, pudiendo distinguirse un total de 93 fragmentos, atribuibles mayormente al Belén negro sobre rojo (29\%) (Figura 6 ) y al Santamariano (13\%). Por otra parte, en esta misma estructura aparecieron restos óseos atribuibles a mamíferos pequeños y medianos, como cérvidos y camélidos $(50 \%)$, comunes en esta región para épocas prehispánicas. También se pudieron identificar restos de animales juveniles y con evidencias de exposición al fuego (calcinado). Asociado a los restos faunísticos se encontró escaso material lítico, un núcleo de calcedonia y dos lascas, cuyas materias primas fueron xilópalo y cuarzo respectivamente. En este recinto se pudo constatar una capa no uniforme de carbón y ceniza, que en ciertos sectores conformaban fogones, localizándose en el área norte la mayor cantidad de materiales arqueológicos. Entre los restos de carbones se pudieron distinguir restos arqueobotánicos tales como marlos de maíz y otros restos carpológicos no identificables debido a su naturaleza fragmentada. Se realizó un fechamiento de radio carbono sobre carbón vegetal (AA 85878, Sector S, cuad. S3-niv.2 a 0,70 m), dando como resultado una edad radiocarbónica calibrada en $523 \pm 39$ AP.

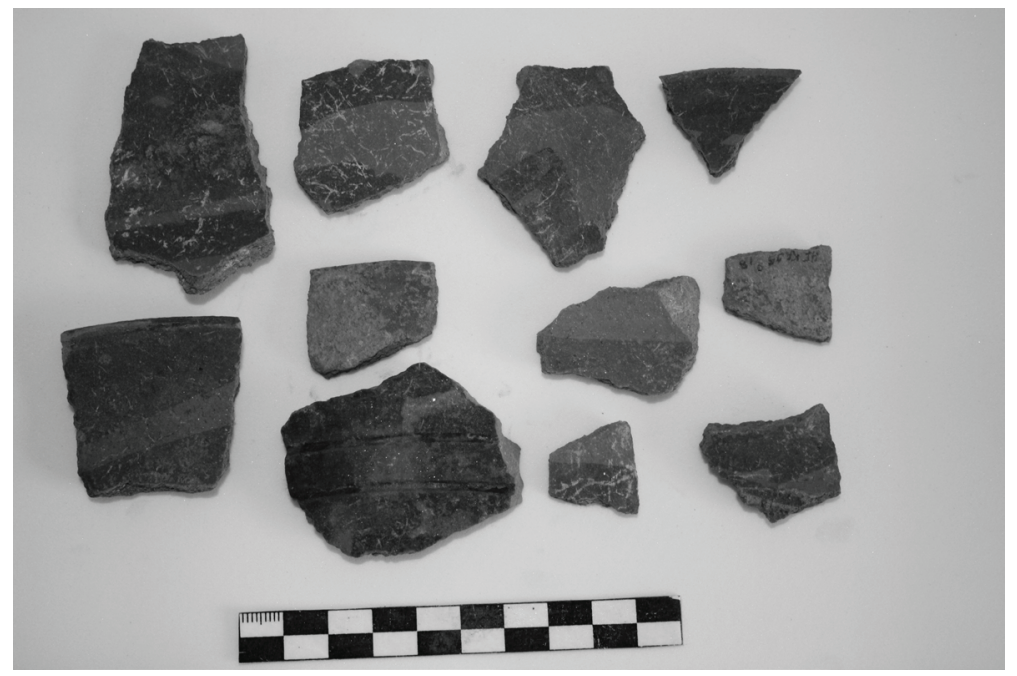

Figura 6: Material cerámico estratigráfico procedente de la kallanka, Tipo cerámico Belén Negro sobre Rojo.

Recinto rectangular 1: En este mismo sector hemos excavado un recinto rectangular $(5 \times 3 \mathrm{~m})$ próximo a la kallanka anteriormente mencionada. Este recinto se encuentra dentro de un mismo RPC, junto a otros recintos más pequeños tanto circulares como rectangulares. En el recinto excavado se determinó la presencia de cerámica incaica en mayor proporción (26\%) y cerámica Belén (19\%). Por otra parte, se hallaron fragmentos santamarianos y toscos u ordinarios en menor cantidad (Figura 7). Asociado a este material se encontraron lascas primarias y secundarias mayorita- 
riamente de basalto, constituyendo el $50 \%$ de la muestra. Por último se localizaron restos de material óseo en su mayoría atribuibles a mamíferos grandes (53\%) representados en la familia Camelidae (guanaco, llama).

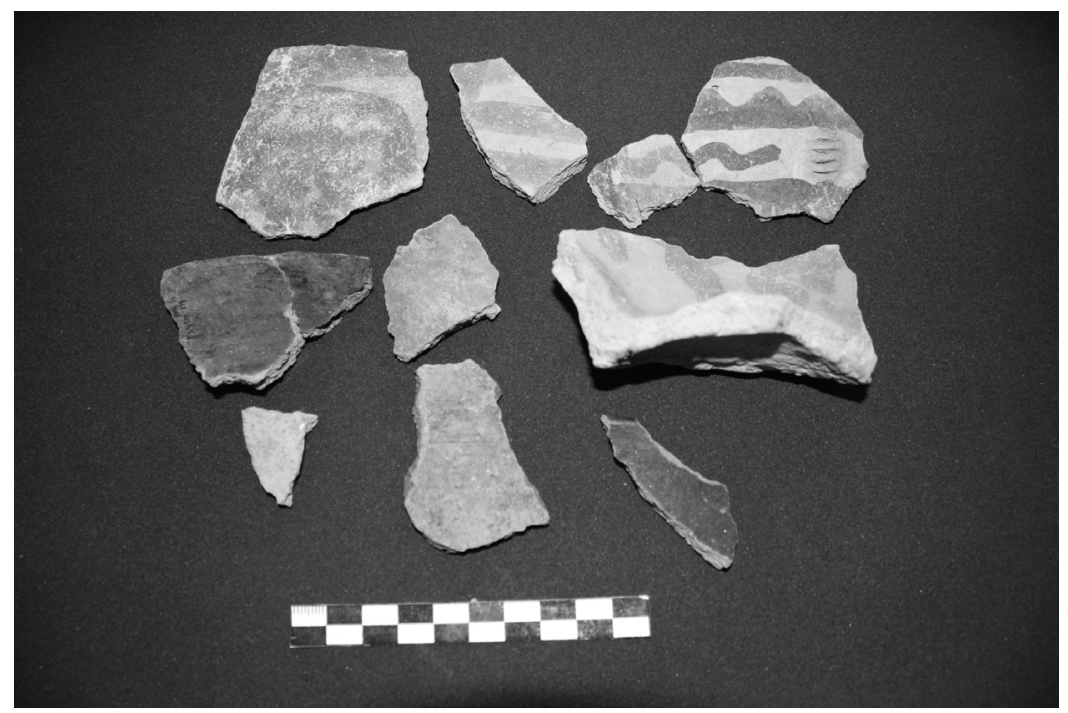

Figura 7: Material cerámico estratigráfico procedente del Recinto Rectangular 1.

En algunos sectores del recinto se puso en evidencia la presencia de fogones con restos de carbones que pudieron ser identificados principalmente como restos de maíz. De aquí se tomo la muestra radiocarbónica AA 85879 de carbón vegetal para la datación de la estructura (Cuadrícula S2, niv. 7, a 0,65 m) dando una edad radiocarbonica de $650 \pm 54$ A.P.

Asimismo es necesario resaltar la zona de albergues o habitaciones del Sector B, una serie de recintos rectangulares y circulares que habrían servido de habitación a personas que habitaran en forma permanente el sitio. En estos recintos se habrían llevado a cabo dos actividades principales como el descanso y la ingesta de alimentos y bebidas. Dan cuenta de ello los fogones y restos de cerámica, óseos y de maíz encontrados en el recinto anteriormente descrito (Lynch 2010: 101).

Torreón: Dentro del Sector A se investigó una estructura circular, de 9,5 m de diámetro, que por sus características constructivas y posición dentro del contexto urbano, originalmente se ha identificado como un torreón de tipo ceremonial (Raffino 1982: 478). Sin embargo, de acuerdo con las evidencias de dicha estructura, como por ejemplo la mayor cantidad de tinajas Belén (32\%) e Inca (24\%) y restos de cerámica tosca $(29 \%)$, algunas con restos de hollín (Figura 8), se ha demostrado que se habrían llevado a cabo diferentes actividades tales como la cocción de algunos alimentos y el almacenamiento de líquidos (Lynch 2010: 119). A su vez, se interpreta como un espacio principal cumpliendo funciones relacionadas a actividades múltiples, ya que se encontraron restos de lascas primarias de descortezamiento. Por otro lado, al estar 
asociado directamente a la plaza principal, se podría decir que dicho espacio estaría vinculado a un tránsito fluido de grandes cantidades de personas realizando tareas de preparación de alimentos, almacenamiento de diferentes granos y líquidos y manufactura de instrumentos líticos, es decir, vinculado a un espacio público y no privado o de albergues de los grupos de elite, como se puede ver en los recintos del Sector B del sitio (Lynch 2010: 290).

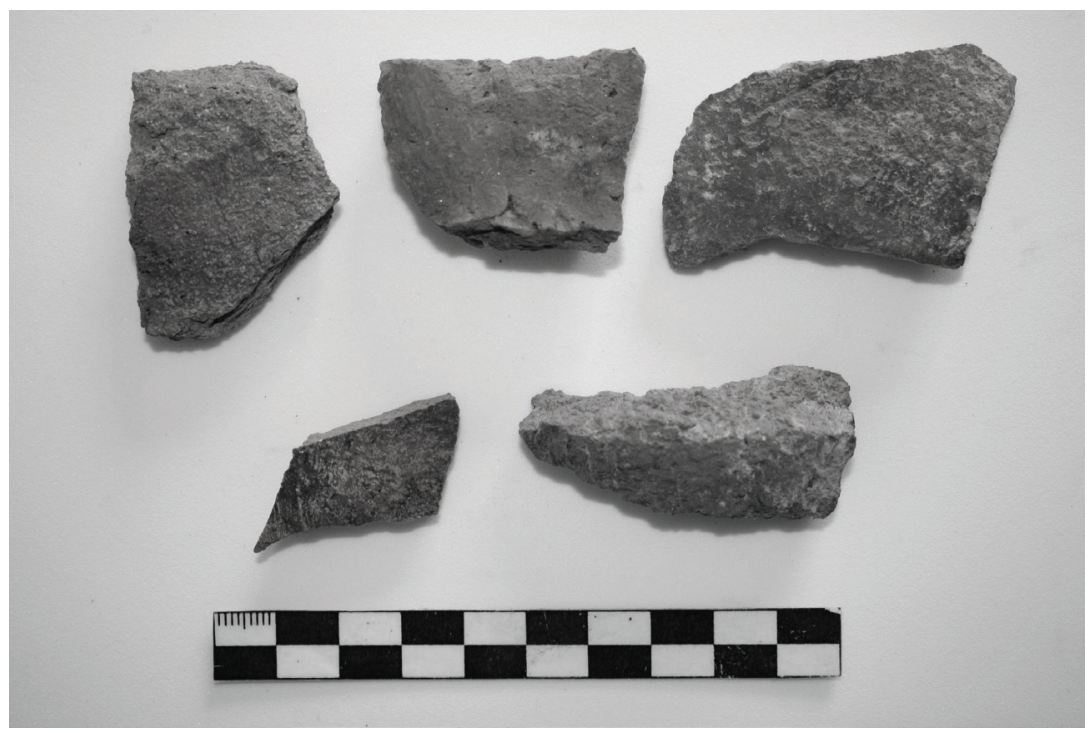

Figura 8: Material cerámico estratigráfico procedente de El Torreón.

\section{Cronología incaica para el NOA: relación del caso de estudio e implicaciones}

Como es bien sabido una de las primeras cronologías para el imperio incaico se estableció a partir de los estudios de John Rowe (1944: 265-284), quien intentó hacia 1940 una cronología absoluta para el desarrollo y expansión del imperio. Después de comparar numerosas descripciones de las sucesiones dinásticas incas encontradas en las crónicas españolas, Rowe concluyó que los datos de Cabello Balboa sobre las sucesiones eran los más «razonables» y «conservadores». A partir de esto, Rowe produjo una lista de los datos sucesorios inca para los últimos cinco monarcas.

Partiendo de estos presupuestos, se estableció la fecha de 1471 d.C., para la anexión del Noroeste Argentino, formando parte del Kollasuyu, atribuyéndola al hijo de Pachacutec, Tupa Inka Yupanqui (Raffino 1981). En años posteriores Raffino y Stehberg (1997) discutirán estos datos, ya que nuevos fechamientos radiocarbónicos y de termoluminicencia para Chile y Argentina evidenciaban una ocupación incaica anterior a lo establecido. En la misma línea, basándose en datos arqueológicos de los últimos años fundamentados en dataciones absolutas de Carbono-14, otros investigadores sostienen que la cronología de Rowe debe retrotraerse por lo menos 50 años 
(Ruiz y Alberck 1998), hasta el comienzo del siglo XV (D'Altroy y Schreiber 2004). La propuesta mejor argumentada llega de la mano de más de 50 fechamientos radiocarbónicos para el Noroeste Argentino que indicarían que el Estado Incaico habría construido instalaciones poco antes del 1400 d.C. (D'Altroy et al. 1998: 284).

Para el caso del sitio Hualfín Inka se dataron las siguientes estructuras: ushnu, una de las kallankas, un torreón y un recinto rectangular, detalladas anteriormente. Se obtuvieron las fechas absolutas con la técnica de AMS sobre carbón vegetal ${ }^{1}$, evidenciando un momento incaico entre los años 1300 y 1477 d.C. (límites máximos). De acuerdo con los hallazgos efectuados en Hualfín Inka y las prospecciones realizadas alrededor del sitio, y teniendo en cuenta que las características arquitectónicas del yacimiento parecen ser enteramente incaicas, se puede argumentar que el sitio estuvo poblado durante la presencia del Estado, relacionándose directamente con las poblaciones locales. Por otro lado, a partir de una rápida observación de las fechas puede observarse que sus rangos ocupan un poco más atrás de lo que se conoce como la ocupación efectiva incaica. Sin embargo, este fechado más antiguo (Rec. 1, AA 85879, $650 \pm 54$ A.P) podría deberse a ciertos problemas que se tienen en el momento de datar el carbón vegetal, ya que la madera utilizada para realizar fuego quizás fue obtenida con anterioridad al momento de uso de la misma, y por este motivo obtenemos un fechado anterior al momento incaico. Es el problema del fenómeno de «madera vieja», donde lo que se quema en un determinado momento, y luego es fechado por C14, estaría mostrando el tiempo de muerte del espécimen que pudo ocurrir mucho tiempo antes. Esto puede pasar por ejemplo en la quema de elementos que formaran parte de una construcción (vigas, pilares etc.), perdurando por mucho tiempo mientras que el material se mantuviera en buen estado hasta que tuviera que ser reemplazado (Marconetto 2007: 211). También puede ocurrir que la madera perteneciera al núcleo de un árbol de gran edad (100 o más años, algo común para especies arbóreas que crecen en el NOA). Este material se encuentra ya lignificado y ha dejado, desde el momento en que se transformó en madera, de intercambiar carbono con el ambiente y por lo tanto ha comenzado a correr el reloj radiactivo.

En este marco, resulta de gran relevancia el aporte que pueda brindar la cronología de otros sitios del Valle de Hualfín, tanto relativa como absoluta, para definir más claramente el rol de Hualfín Inka a nivel regional. Entre los sitios mencionados en el desarrollo de los antecedentes en la investigación incaica en todos los casos se cuenta con fechados radiocarbónicos y con información acerca de sus características arquitectónicas y de los materiales de sus excavaciones. Sin embargo, cada sitio merece un tratamiento particular, teniendo en cuenta no sólo el avance logrado en cuanto al método de datación radiocarbónica desde los primeros trabajos hasta hoy, sino también la información arqueológica que se ha ido acumulando en los últimos tiempos.

1 Las muestras han sido realizadas en el Laboratorio NSF de AMS, Edificio de Física, Universidad de Arizona, Estados Unidos. 


\section{Consideraciones finales}

A partir de las excavaciones realizadas en el sitio Hualfín Inka, se ha podido observar que el sitio presenta una sola ocupación, correspondiente al momento incaico. La construcción del sitio durante las primeras décadas de la ocupación incaica del Noroeste Argentino estaría apoyada por fechas radiocarbónicas obtenidas tanto en el uhsnu como en otras estructuras principales del emplazamiento. La escasez y características del registro material sostienen, por otra parte, la hipótesis de una ocupación poco intensa en la que las prácticas estatales habrían tenido una escasa relevancia (Lynch 2010: 305). Esto contrasta notablemente con una arquitectura planificada de acuerdo a los cánones propios del Tawantinsuyu. Es muy probable que el sitio haya perdido importancia con el correr del tiempo, momento en el cual alcanza su máxima expresión el sitio El Shincal. Este último emplazamiento ha demostrado una importancia trascendental que lo destaca al interior del Kollasuyu (Giovannetti 2009; Raffino 2004). Plazas centrales con grandes dimensiones, estructuras arquitectónicas planificadas para grandes reuniones, entre numerosos elementos de carácter simbólico-ritual, demuestran la realización de reuniones festivas muy similares a las conocidas para los Andes Centrales (Moore 1996). Las investigaciones más recientes dan cuenta de un mayor soporte empírico en relación a las festividades y eventos de congregación propiciados por el Estado (Giovannetti 2009). De esta manera, el análisis del sitio Hualfín Inka dentro de la dinámica política del Estado da cuenta, no sólo de diferencias en la forma en que el Estado habría operado en los distintos territorios y del carácter de la relación con las poblaciones locales, sino también de los matices del proceso histórico involucrado en el establecimiento incaico en esta región del Noroeste Argentino.

\section{Referencias bibliográficas}

BALESTA, Bárbara y Federico WynBeldT

2010 «La Loma de Ichanga: visibilidad, defensibilidad y abandono en el valle de Hualfín (Depto. de Belén, Prov. de Catamarca, Argentina)». Revista Española de Antropología Americana 40 (1): 53-71.

BRuch, Carlos

1904 «Descripción de algunos sepulcros calchaquíes. Resultado de las excavaciones efectuadas en Hualfín (Provincia de Catamarca)». Revista del Museo de La Plata 11: $13-27$.

CAMinos, R.

1979 «Sierras Pampeanas Noroccidentales, Salta, Tucumán, Catamarca, La Rioja y San Juan», en Geología Regional Argentina, J. C. M. Turner, coord., pp. 225-282. Córdoba: Academia Nacional de Ciencias.

D'Altroy, Terence

1987 «Transitions in Power: Centralization of Wanca Political Organization under Inka Rule». Ethnohistory 34: 78-102. 
D'Altroy, Terence, Ana María Lorandi y Verónica Williams

1998 "Ceramic Production and Use in the Inka Political Economy», en Andean Ceramics: Technology, Organization and Approaches, I. Shimada, ed., pp. 284-312. Filadelfia: Museum of Archaeology and Anthropology, University of Pennsylvania.

D'Altroy, Terence y Katharina SchreIBER

2004 «Andean Empires», en Andean Archaeology, Helaine Silverman, ed., pp. 255-278. Oxford: Blackwell Publishing.

Dillehay, Tom D. y Patricia Netherly

1988 «Introducción», en La frontera del Estado Inka, Tom D. Dillehay y Patricia Netherly, comps., pp. 1-33. Oxford: BAR Internacional Series 442.

FARRINGTON, Ian

1999 «El Shincal: un Cusco del Kollasuyu», en Actas del XII Congreso Nacional de Arqueología Argentina, Cristina Diez Marín, ed., Tomo I, pp: 53-62. La Plata: Universidad Nacional de La Plata.

GiovannetTi, Marco Antonio

2009 Articulación entre el sistema agrícola, redes de irrigación y áreas de molienda como medida del grado de ocupación Inka en El Shincal y Los Colorados (prov. de Catamarca). Tesis doctoral inédita. Facultad de Ciencias Naturales y Museo. La Plata: Universidad Nacional de La Plata.

GonzÁlez Bonorino, Félix

1950 «Algunos problemas geológicos de las Sierras Pampeanas». Revista de la Asociación Geológica Argentina 5 (3): 81-110.

GonzÁlez, Alberto Rex y George. L. Cowgill

1975 «Cronología arqueológica del Valle de Hualfín, Prov. de Catamarca, Argentina. Obtenida mediante el uso de computadoras». Trabajo presentado en el $1^{\circ}$ Congreso Nacional de Arqueología Argentina. Rosario de Santa Fe, Buenos Aires: Museo Histórico Provincial «Dr. Julio Marc».

GonZÁlEZ, Luis y Myriam TARRAGó

2004 «Dominación, resistencia y tecnología: la ocupación incaica en el noroeste argentino». Chungará 36 (2): 393-406.

HYSLOP, John

1990 Inka Settlement Planning. Austin: University of Texas Press.

IBARRA GRASSO, Dick Edgar

1994 Sudamérica indígena. Buenos Aires: Editorial Tea.

LYNCH, Julieta

2010 La construcción del paisaje y la organización del espacio en el sector Norte del Valle de Hualfin, Provincia de Catamarca. Tesis doctoral inédita. Facultad de Ciencias Naturales y Museo. La Plata: Universidad Nacional de La Plata.

Lynch, Julieta, Marco Antonio Giovannetti, María Cecilia PÁEz

2010 «Ushnus de las provincias del sur del Tawantinsuyu. Comparación entre las estructuras de los sitios El Shincal y Hualfín Inka en el centro de Catamarca (Argentina)». Revista de Arqueología Americana 28: 49-83. 
LYNCH, Julieta y Virginia LYNCH

2010 «Análisis de los materiales líticos y aprovisionamiento de materias primas del sitio Hualfín Inka (prov. de Catamarca)», en Actas del XVII Congreso Nacional de Arqueología Argentina, Tomo IV: 1685-1690. Mendoza: Zeta Editores.

Lynch, Julieta, Virginia Lynch, Victoria Lissa y Ramiro PÁEZ

2007 «Primeros avances de los materiales recuperados del sitio Hualfín Inka, depto. Belén, provincia de Catamarca». Revista Pacarina, Número especial, Tomo II: 525-532.

LyNCH, Julieta, Virginia LyNCH y Ramiro PÁEZ

2006 «Análisis preliminar de los materiales recuperados del sitio arqueológico Hualfín Inka (Departamento Belén, Catamarca)», en Actas del III Congreso de Historia de Catamarca, Tomo I, pp. 197-203. San Fernando del Valle de Catamarca: Editorial Científica Universitaria.

Lynch, Julieta y María Cecilia PÁEz

2011 «Características de la relación local-estatal en el sitio Hualfín Inka (Depto. Belén, prov. De Catamarca, Argentina). Inferencias a partir del análisis cerámico». Revista Arqueoweb 13: 55-73.

Marconetto, María B.

2007 «Aportes de la antracología a la cronología del valle de Ambato», en Investigaciones arqueobotánicas en Latinoamérica: estudios de casos y propuestas metodológicas, B. Marconetto, N. Oliszewski y P. Babot, eds., pp. 197-218. Córdoba: Centro Editorial de la Facultad de Filosofía y Humanidades - UNC.

Meddens, Frank M.

1997 «Function and Meaning of the Usnu in Late Horizon Peru». Tawantinsuyu 3: 4-14. MoOre, John

1996 «The archaeology of plazas and the proxemics of ritual: three Andean traditions». American Anthropologist 98 (4): 789-802.

NiELSEN, Axel

2006 «Plazas para los antepasados: descentralización y poder corporativo en las formaciones políticas preincaicas de los Andes Circumpuneños». Estudios Atacameños 31: 63-89.

PizARro, Pedro

1978 Relación del descubrimiento y conquista del Perú [1571]. Lima: Pontificia Universidad Católica del Perú.

RAFFino, Rodolfo A.

1981 Los inkas del Kollasuyu. Origen, naturaleza y transfiguraciones de la ocupación Inka en los Andes Meridionales. La Plata: Ed. Ramos Americana.

2004 El Shincal de Quimivil. Catamarca: Editorial Sarquís.

Raffino, Rodolfo A., Ricardo Alvis, Lidia Baldini, Daniel Olivera y Gabriela Raviña

1982 «Hualfín-El Shincal-Watungasta. Tres casos de urbanización inka en el N.O. argentino», en Actas del IX Congreso Nacional de Arqueología. Sociedad chilena de Arqueología, pp. 470-497. La Serena: Museo arqueológico de La Serena. 
RAFFino, Rodolfo y Rubén SteHberG

1997 «El Tawantinsuyu y sus fronteras», en Actas y Trabajos cientificos del XI Congreso Peruano del Hombre y la Cultura Andina «Augusto Cardich», H. Olazábal y G. Palomino eds. Tomo I, pp. 338-361. Lima: Universidad Nacional «Hermilio Valdizán» de Huánuco - Universidad Nacional de La Plata - Centro de Estudios Histórico-Militares de Perú.

Rowe, John H.

1944 An Introduction to the Archaeology of Cuzco. Papers of the Peabody Museum of American Archaeology and Ethnology, Vol. $27 \mathrm{n}^{\circ}$ 2. Cambridge: Harvard University.

Ruiz, Marta Susana y María Ester Albeck

1998 Los Inkas. Espacio y cultura. San Salvador de Jujuy: Editorial Universidad Nacional de Jujuy.

Silva Olivares, Jorge E.

1957 «Noticias sobre investigaciones en piedras tacitas». Publicaciones del Museo y de la Sociedad Arqueológica de La Serena. Boletín 9: 24-26.

STEHBERG, Rubén y Arturo RodRíguez

1995 «Ofrendas mapuche-incaicas en el Cerro Tren-Tren de Doñihue, valle de Cachapoal». Tawantinsuyu 1: 29-35.

WiLLIAMs, Verónica

2004 «Poder estatal y cultura material en el Kollasuyu». Boletín de Arqueología PUCP 8: 209-245.

Zuidema, R. Tom

1979 «El ushnu». Revista de la Universidad Complutense 117: 317-362. 